Research Article

\title{
Study on Preservation of Chilled Beef with Natural Essential Oil Nanocapsules
}

\author{
Bin Xi $\mathbb{D}^{1,2}$ Yaqin Gao, ${ }^{1,2}$ Tianfen Guo, ${ }^{1,2}$ Weihong Li, ${ }^{1,2}$ Xiaoling Yang, ${ }^{1,2}$ \\ and Tianqing $\mathrm{Du}^{1,2}$ \\ ${ }^{1}$ Lanzhou Institute of Husbandry and Pharmaceutical Sciences, Chinese Academy of Agricultural Sciences, Lanzhou 730050, \\ Gansu, China \\ ${ }^{2}$ Quality Safety Risk Assessment of Animal Products, Ministry of Agriculture, Lanzhou 730050, Gansu, China
}

Correspondence should be addressed to Bin Xi; xibin@caas.cn

Received 7 August 2020; Revised 21 September 2020; Accepted 14 October 2020; Published 20 November 2020

Academic Editor: Tifeng Jiao

Copyright (C) 2020 Bin Xi et al. This is an open access article distributed under the Creative Commons Attribution License, which permits unrestricted use, distribution, and reproduction in any medium, provided the original work is properly cited.

Beef is rich in amino acids and vitamin B6, carnitine, potassium, protein, and other nutrients. It can improve the body's ability to resist disease and is especially suitable for growth, development, and postoperation and postrehabilitation care. Under such circumstances, the demand for beef consumption in various countries continues to grow steadily. At present, domestic beef prices continue to rise, and beef supply is insufficient. In addition, fresh beef is easy to be infected with microorganisms in the process of cold storage, which makes fresh beef deteriorated. Therefore, it is very important to add preservatives to prolong the shelf life of chilled beef. In this paper, the preservation of chilled beef with nanocapsules made of natural essential oil from plant extracts was studied. In this study, cumin, Zanthoxylum, ginger, cinnamon, clove, and thyme were selected to study the effect of six kinds of essential oils on beef preservation through comparative experiments. On the basis of such research data, the six kinds of essential oils were compounded, respectively, and different nanoessential oil capsules were applied to the fresh-keeping of chilled beef to make different kinds of nanoessential oil capsules. Through the experiment, the compound essential oil with better preservation effect was obtained. And through the comparison, cinnamon essential oil has obvious antibacterial activity, while ginger essential oil has the worst antibacterial effect. The $\mathrm{pH}$ value of beef can be changed and the degradation rate of protein in beef will be slowed down by applying appropriate amount of decomposed plant essential oil to beef samples. Through the above experimental results, we applied the compound essential oil to the preservation of cold and fresh beef at nanometer level and found that the effect was significant, which was worthy of application in major beef products processing plants.

\section{Introduction}

Meat and meat products play an important role in people's life. With the gradual improvement of people's living standards, food safety has gradually become the focus of attention. Especially in recent years, the problem of food safety has become increasingly prominent. Not only do people have higher and higher requirements for the preservation technology of meat and meat products, but also China is a country with a large population in the world and the largest meat production and consumption market in the world. Therefore, researchers attach great importance to the research on the preservation technology of meat, chicken, and meat products. In our daily life, the common raw meat is cold fresh meat, normal temperature meat, and frozen meat. We call frozen meat when the storage temperature is lower than $-23^{\circ} \mathrm{C}$ and the internal temperature of meat is lower than $-15^{\circ} \mathrm{C}$ [1]. Normal temperature meat refers to the normal temperature meat directly slaughtered. The definition of cold fresh meat [2] refers to the fresh meat which is slaughtered in strict accordance with the national quarantine standards and finally matures after a refrigeration process of about $4^{\circ} \mathrm{C}$. During the storage of chilled meat, due to the role of active enzymes in meat, protein is decomposed into peptide chain and small molecule amino acid molecules [3]. The shelf life of hot meat is shorter than that of cold meat 
because it is easier to be contaminated by bacteria. Although the growth of microorganisms in frozen meat is inhibited, frozen meat still has the characteristics of poor sensory quality and nutrient loss after thawing. Therefore, cold and fresh meat with its excellent quality gradually occupies an important proportion in the market. Cold fresh meat is favored by consumers because of its delicious quality and attractive appearance. Because cold meat is inevitably processed by bacterial contamination, although cold meat has been kept in a low-temperature state, for most chilly bacteria, it is still growing and reproducing, so it is particularly important to extend the cooling of meat. The preservation time replaces adding preservatives.

Beef and its products have the advantages of high protein content and rich amino acids, which are loved by consumers at home and abroad. Beef is an important source of protein in daily diet, which can provide rich amino acids for human daily metabolism. In addition, the peptide produced by bovine belt can promote metabolism and maintain health in human metabolism. At the same time, beef is rich in iron, tin, zinc, copper, manganese, and other trace elements. These trace elements play an important role in human metabolism and the formation of antioxidant enzymes. The fatty acids and fat-soluble vitamins contained in beef are also necessary for human daily diet. In 2018, China's beef production reached 6.89 million tons, ranking the third in the world, accounting for $10 \%$ of the world's total. In recent years, in the production and sales of domestic fresh meat, the proportion of cold fresh meat is gradually increasing [4]. Therefore, extending the shelf life of chilled meat is of great significance to the development of chilled meat. Fresh beef is easy to be polluted and deteriorated by microorganisms during cold storage. Oxidation and microbial contamination are the main reasons for the deterioration of frozen beef.

On the one hand, chemical preservatives can inhibit the growth and reproduction of microorganisms; on the other hand, they can prolong the deterioration of food or inhibit biological metabolism, which is called chemical preservatives [5]. Chemical synthetic preservatives are favored by consumers because of their low price. However, some chemical preservatives are harmful to human body. For example, nitrite, as a kind of chemical preservative, can not only inhibit the growth of microorganisms, but also make food more colorful. However, the long-term consumption of nitrite will affect the normal function of red blood cells, resulting in the difficulty of oxygen transport. In addition, nitrite [6] is a chemical preservative and its use is limited. It is nontoxic in use. In case of excessive use or under certain conditions into nitrosamines, nitrosamines have the risk of cancer. At present, the main chemical preservatives used in China are organic acids and their salts, such as sorbic acid and its potassium salt, dehydroacetic acid and its sodium salt, and benzoic acid and its sodium salt. Although chemical preservatives are widely used, traditional chemical preservatives may be replaced by natural, nontoxic, and safe natural preservatives with the prominent safety problems of food additives. In recent 20 years, natural preservatives extracted from plants, animals, and microorganisms have been widely used in practice and recognized by consumers.
At present, natural preservatives are mainly studied in China. Most of these natural preservatives are extracted from plants or microorganisms, with good antibacterial effect, practicality, and high safety. Natural preservatives come from animals, microorganisms, and plants in nature.

The main components of cinnamon essential oil [7] are cinnamaldehyde, cinnamyl ester, salicylaldehyde, etc. In recent years, cinnamon essential oil has been widely used in preservation research because of its broad-spectrum antibacterial and excellent antioxidant properties. Thyme essential oil is extracted from the stems and leaves of thyme. Thyme is characterized by a strong aroma when it blooms. Thyme can inhibit bacteria and scavenge free radicals. Thyme essential oil not only has a strong inhibitory effect on common bacteria in life, but also eliminates free radicals in food and prevents food from being oxidized [8]. Ginger is an important life spice, which is widely used in clinical treatment of traditional Chinese medicine [9]. As a kind of medicinal plant and spice, clove has been found to be a natural food preservative in recent years. At present, many reports have confirmed that clove volatile oil has good antibacterial and antioxidant properties and is a natural antioxidant and antibacterial agent. Clove essential oil has strong special flavor and is volatile, insoluble in water, and sensitive to light, oxygen, and temperature. These factors greatly restrict the application of clove essential oil in food preservation. In order to improve its stability in food processing and cover up its bad flavor, microencapsulation of core materials can effectively solve this problem. Cumin is a kind of spice, mainly used for meat seasoning, but it also can be used in the processing and production of various foods. It is a natural source of medicine and food. The results showed that the bacteria treated with natural essential oil had some abnormal phenomena, such as cell shrinkage, local deformation, cell wall and membrane rupture, and cell system loss. The main components of Zanthoxylum bungeanum are flavonoids, volatile oil, alkaloids, and so on. These substances are very common in plants and have inhibitory effects on spoilage bacteria and pathogenic bacteria in food. Zanthoxylum bungeanum will become one of the important sources of natural food preservatives.

Due to the different types and concentrations of preservatives, the antibacterial activity of preservatives will also change greatly. Therefore, it is not possible to inhibit the growth of all microorganisms by one preservative alone. In order to obtain better preservatives, several kinds of preservatives are commonly used to combine and play the synergistic antibacterial and antioxidant effects of different preservatives. The combination of different preservatives can not only obtain better preservation effect, but also reduce the amount of preservatives under the same preservation effect. Compound natural preservatives are safer, more broad-spectrum antibacterial and can prevent antibiotic resistance. In this paper, based on the study of different essential oils on the preservation of chilled beef, the essential oils were compounded to obtain the composite essential oil nanocapsules with better preservation effect. 


\section{Preservation Effect of Different Essential Oils on Chilled Beef}

2.1. Extraction of Plant Essential Oil. The traditional extraction methods of plant essential oil [10] include solvent extraction, absorption, and pressing. The extraction of plant essential oil mainly depends on the hydrophobicity or mild degree of target molecules, and the extraction rate of most essential oils is less than $5 \%$. Therefore, there are many innovative nonthermal extraction methods, such as ultrasound, high voltage, and pulsed electric field assisted extraction, to overcome the above constraints. Water distillation was used in this experiment. The raw material from the factory is crushed by a small motor and passed through 60 mesh. The ratio of plant material and distilled water is $1: 100$, and the distilled water is soaked at $100^{\circ} \mathrm{C}$ for 1 hour. The distillate is condensed by the condensate and collected. Anhydrous sodium carbonate was used as desiccant for dehydration and drying. The essential oil was collected and stored at $4^{\circ} \mathrm{C}$ away from light.

The cumin oil, Zanthoxylum essential oil, cinnamon essential oil, clove essential oil, ginger essential oil, and thyme essential oil were diluted with $0.5 \%$ Twain 100 solution to make cumin essential oil, Zanthoxylum essential oil, cinnamon essential oil, clove essential oil, ginger essential oil, and thyme essential oil at concentrations of $0.1 \%$, $0.2 \%, 0.3 \%, 0.4 \%, 0.5 \%, 0.6 \%, 0.7 \%, 0.8 \%, 0.9 \%, 0.9 \%, 0.9 \%$, $0.9 \%, 0.9 \%, 0.8 \%$, and $0.9 \%$, respectively. After the treatment solution is prepared, put them into the refrigerator at $4^{\circ} \mathrm{C}$ in the dark environment.

2.2. Configuration of Culture Medium. Take $10 \mathrm{~g}$ as the basic unit, put the sample beef, pure salt, peptone, and agar powder into $1000 \mathrm{ml}$ distilled water, respectively, according to the ratio of $1: 1: 2:(2-3)$, heat them, and stir all mixture for sterilization.

2.3. Preparation of Bacterial Suspension. Activated strain: sterilize the test tube with appropriate amount of culture medium, and then place it until it solidifies to form an inclined plane. Then the strain was transplanted to the slope of the medium under aseptic conditions. Finally, the treated medium was put into the biochemical incubator for one night.

Preparation of bacterial suspension: the bacteria cultured on the slope of the strain were extracted into $0.1 \mathrm{~L}$ liquid medium and cultured for $24 \mathrm{~h}$ to produce bacterial suspension. Then, the concentration of colony count can be calculated by plate counting method, which is about 106-108 CFU/g.

2.4. Determination of Bacteriostatic Zone. Firstly, a filter paper with a diameter of $0.1 \mathrm{~cm}$ was prepared, and $1 \mathrm{ml}$ of bacterial suspension was absorbed with the prepared filter paper and added into the culture dish obtained by 2.3 . Then, the filter paper with the prepared essential oil was put into the culture dish. After the above operation, put the culture dish into the incubator maintained at normal temperature. After 24 hours, the diameter of inhibition zone was measured.

2.5. Determination Method of MIC. Take $2 \mathrm{ml}$ of the prepared bacterial suspension and add it to the sterilized clean plate, mix it with nutrient agar in the culture dish, and finally add appropriate amount of preservative solution to mix it evenly. In this experiment, two parallel tests were performed with each concentration inverted for one day. The minimum inhibitory concentration (MIC) is the concentration of preservative when there is no colony in the dish. The results showed that the antibacterial effect was inversely proportional to MIC.

2.6. Orthogonal Experiment. As shown in Table 1, the minimum inhibitory concentrations of six essential oils against Pseudomonas fluorescens were obtained, and the optimal compound concentration of essential oils was further studied by orthogonal experiment.

\subsection{Study on the Preservation Effect of Compound Preservative} on Chilled Beef. Choose compound preservative: take about $50 \mathrm{~g}$ fresh beef and apply $0.1 \%$ Tween 100 evenly on fresh beef. The above operation was carried out once and twice in total. When the surface of beef is dried, the dried beef is weighed on the weighing table, and the water absorption rate can be calculated as $7.0 \%$. According to the calculated water absorption and the results obtained in Section 2.6, 1, 2, 3, 4, 5 , and 6 in the orthogonal experiment were prepared in 1, 2, 4,8 , and 16 times of each formula, respectively, and then stored for $24 \mathrm{~h}$. Then TVB-N was used as the evaluation index of storage and preservation effect to select a more suitable proportion scheme for subsequent experiments. $0.1 \%$ Tween 100 was used as control, and a blank group was set up without coating treatment.

For sample treatment, take fresh beef and put it into refrigerator at $4^{\circ} \mathrm{C}$ to make chilled beef. The knife, plastic chopping board, plastic tray, and preservative film were sterilized and disinfected. Then take out the prepared cold and fresh beef, on the treated table, the beef is processed into small pieces of about $50 \mathrm{~g}$, and then put them on the treated plastic tray, and they are randomly divided into three groups: blank group, experimental group, and control group. Evenly spread the compound preservative solution determined in 2.7 on $50 \mathrm{~g}$ beef pieces and repeat the above operation again after 10 minutes. Then the control group was treated with $0.1 \%$ Tween 100 , and the blank group was placed without any treatment. After all the steps, put the processed beef sample into the aseptic room, dry both sides of the beef sample, and then wrap it with plastic film and put it in the refrigerator at $4^{\circ} \mathrm{C}$. At $0 \mathrm{~d}, 4 \mathrm{~d}, 8 \mathrm{~d}, 12 \mathrm{~d}$, and $16 \mathrm{~d}$ after treatment, 3 samples were taken from each treatment group for index determination.

Determination of cooking loss was improved according to Rezaeinia et al. [11]. Take appropriate amount of meat pieces $x 0$, put them into the cooking bag and seal them, and 
TABLE 1: Orthogonal experiment table of six essential oils.

\begin{tabular}{|c|c|c|c|c|c|c|}
\hline \multirow[b]{2}{*}{$\begin{array}{l}\text { Experiment } \\
\text { number }\end{array}$} & \multicolumn{6}{|c|}{ Factor } \\
\hline & $\begin{array}{l}\text { Cumin essential } \\
\text { oil concentration }\end{array}$ & $\begin{array}{c}\text { Concentration of } \\
\text { Zanthoxylum } \\
\text { bungeanum essential } \\
\text { oil }\end{array}$ & $\begin{array}{l}\text { Concentration of } \\
\text { refined cinnamon } \\
\text { oil }\end{array}$ & $\begin{array}{l}\text { Concentration of } \\
\text { clove essential oil }\end{array}$ & $\begin{array}{l}\text { Thyme essential } \\
\text { oil concentration }\end{array}$ & $\begin{array}{l}\text { Ginger essential } \\
\text { oil concentration }\end{array}$ \\
\hline 1 & 1 & 1 & 1 & 1 & 1 & 1 \\
\hline 2 & 1 & 2 & 2 & 2 & 2 & 2 \\
\hline 3 & 1 & 3 & 3 & 3 & 3 & 3 \\
\hline 4 & 1 & 1 & 1 & 1 & 1 & 3 \\
\hline 5 & 1 & 2 & 2 & 2 & 1 & 3 \\
\hline 6 & 1 & 3 & 3 & 3 & 1 & 3 \\
\hline 7 & 2 & 1 & 3 & 1 & 1 & 2 \\
\hline 8 & 2 & 2 & 2 & 3 & 1 & 2 \\
\hline 9 & 2 & 3 & 1 & 2 & 1 & 2 \\
\hline
\end{tabular}

put them into water at $75^{\circ} \mathrm{C}$. Observe the temperature of the meat pieces. When the central temperature of the meat pieces rises to $65^{\circ} \mathrm{C}$, maintain this state and continue to cook. After 40 minutes, take them out, use filter paper to absorb the moisture on the surface of the meat pieces, and then place the meat pieces in the room to let them cool to the indoor temperature. Then the meat was weighed and the weight was recorded as $\mathrm{X}_{-} 1 \mathrm{~g}$.

Determination of centrifugal loss rate: weigh $0.01 \mathrm{~kg}$ sample, wipe the moisture on the surface of the sample, and put it into the centrifugal tube for weighing after grinding. After weighing, it was centrifuged. After centrifugation, take out the centrifuge tube to clean the water in it. Pay attention to the water on the surface of the centrifuge tube which should also be wiped dry. Finally, the sample and the centrifuge tube are put together for weighing. Centrifugal loss rate is the most intuitive index to measure the water holding capacity of meat, and it is also a very important index.

Determination of meat color [12] was performed according to Wang. After the meat is taken out of the refrigerator, the color difference meter is used to measure the meat on the surface at five different positions randomly, and the value of the color difference meter is recorded. Each piece was measured five times; then all the values were added and divided by 5 .

Determination of TBA value was performed using spectrophotometry; refer to GB/t5009.81-2019.

Determination of shear force was performed as follows: take $5 \mathrm{~cm}, 50 \mathrm{~g}$ of meat, clean the connective tissue and fat on the surface of the meat, then put it into the cooking bag and seal it, and put it into the water at $75^{\circ} \mathrm{C}$. Then take it out and place it in the indoor environment and let it cool to the indoor temperature. Then, a $1.05 \mathrm{~cm}$ diameter sampler was used to take cylindrical samples along the direction of muscle fibers. At least three cylindrical samples were taken from each meat sample. The force of meat samples was measured by tenderness meter. To ensure the accuracy of the results, each column sample should be measured at least 5 times.

MFI determination was improved according to Delgado's method. Take $0.01 \mathrm{~kg}$ meat sample, add $0.08 \mathrm{~L}$ MFI buffer ice bath homogenization and then centrifugate it, and then remove the supernatant. The precipitate was homogenized with MFI buffer and then centrifuged, and the supernatant was removed. $0.05 \mathrm{~L}$ buffer suspension was used for precipitation, and $0.05 \mathrm{~L}$ buffer solution was used to help filter 300 mesh nylon. The protein concentration of myofibrillar extract was determined by double contraction urine method, and the white concentration was adjusted to $0.1 \mathrm{mg} / \mathrm{ml}$. The absorbance was measured at $550 \mathrm{~nm}$. Finally, the measured data is multiplied by 210 .

Determination of lysosomal cathepsin activity: using the method provided in the kit, the meat sample was treated with PBS solution, and then the corresponding reagent was added according to the method provided. The absorbance and protein concentration were measured at $440 \mathrm{~nm}$, and then the enzyme content $(\mu / \mathrm{g})$ was calculated.

\section{Preparation of Natural Nanoessential Oil Capsules}

Technology is based on microencapsulation technology. Microcapsule technology is a kind of micropackaging technology, which uses polymer film to encapsulate microimages of gas, liquid, and solid [13]. The materials purchased by backpacks are called new material packaging, while polymers rich in new materials are called monetary talents. Generally speaking, the diameter of microcapsules is between 1 and $35 \mathrm{~m}$, and nanocapsule technology can prepare nanomicrocapsules. Compared with traditional microcapsules, nanocapsules have good biocompatibility, targeting, and sustained release, which can effectively reduce the sensitivity of bioactive substances and improve the bioavailability of bioactive substances. The main advantages of nanocapsules in food are to slow down the volatilization rate of volatile compounds, delay the loss time of aromatic components in spices, and cover up the release of some undesirable flavor components. It can greatly prolong the effective time of bioactive substances, reduce the effective addition of bioactive substances, reduce the toxic and side effects of some active substances, effectively improve the stability of bioactive substances, and prevent sensitive substances from being damaged by light, oxygen, and temperature. In the food industry, as a new carrier of functional active substances, nanocapsules increase the 
available range of these substances, especially for men. Soluble substances play a good role in compatibilization and improve its compatibilization effect, so that it can be better used by people.

The selection of microcapsule wall materials has always been the focus of research, and the application effect of microcapsules often depends on the selection of wall materials, because the wall materials will affect the controlled release of microcapsules and the permeability, solubility, fluidity, and other properties of microcapsules. Therefore, the selection and preparation of wall materials are the key technology in the field of micropackaging and also the premise of realizing the micropackaging technology. Generally speaking, the selection of wall materials of microcapsules should follow the following principles: the wall materials and core materials should keep chemical stability without chemical reaction, so that the wall materials have good mass transfer performance and stable extrusion resistance, and the whole microcapsule has certain solubility, permeability, and stability. If industrial development, largescale production, and low-cost wall materials are involved, the research and development of low-cost wall materials can be realized, and the preparation process is a necessary condition. Traditional wall materials of microcapsules generally refer to natural polymer materials. They are nontoxic, biocompatible, film-forming, and cheap. They are the most commonly used wall materials for microcapsules. Generally speaking, as long as the materials have good filmforming properties and certain strength and toughness and can be coated around the new materials, they can be used as microcapsules of natural polymer materials, mainly including carbohydrates, proteins, and fats.

Chitosan [14] is a kind of high molecular polysaccharide, and its molecular structure is very similar to that of glycosaminoglycan. Chitosan has unique molecular structure and chemical properties. In nature, only chitosan is a kind of natural polymer material with positive charge and biodegradation. For example, crabs and shrimps are widely found in crustaceans of marine arthropods, such as insects, fungi, and algae, as well as in the cell walls of higher animals and plants. They are nontoxic, tasteless, and irritant. The degree of deacetylation of chitosan is more than $90 \%$, which can be called medical grade chitosan.

Chitosan nanocapsules were prepared by ionic gel method. Chitosan was dissolved in $2 \%$ glacial acetic acid to prepare $6 \mathrm{mg} / \mathrm{ml}$ chitosan solution, which was stirred by magnetic force at $55^{\circ} \mathrm{C}$ for $1 \mathrm{~h}$ and filtered with $0.5 \mu \mathrm{m}$ microporous filter paper, and the $\mathrm{pH}$ of chitosan filtrate was adjusted to a proper value with $3 \mathrm{~mol} / \mathrm{L}$ sodium hydroxide solution. After the completion of the above operation, $60 \mathrm{ml}$ of the prepared chitosan solution was extracted, and an appropriate amount of Tween 70 was added into it, stirred at $55^{\circ} \mathrm{C}$ for $0.5 \mathrm{~h}$, and then put into the room for cooling to the indoor temperature. Then the essential oil was added into the absolute ethanol to obtain the $60 \mathrm{mg} / \mathrm{ml}$ essential oil solution. Then the essential oil solution was added into the chitosan solution. The essential oil solution was stirred at room temperature for $0.5 \mathrm{~h}$. Then, $2.0 \mathrm{mg} / \mathrm{ml}$ sodium polyphosphate solution was added into the chitosan essential oil emulsion drop by drop. After stirring at room temperature for $1 \mathrm{~h}$, the chitosan essential oil nanocapsule dispersion was obtained. After centrifugation at $13000 \mathrm{rpm}$ for $0.5 \mathrm{~h}$, nanoparticles were prepared as the capsules will float in distilled water and freeze-dry for analysis.

\section{Results and Discussion}

4.1. Antibacterial Activity of Natural Essential Oil. As shown in Figure 1, the antibacterial activity of the six essential oils on the two bacteria is relatively obvious, among which cinnamon oil has the strongest inhibitory effect on bacteria, and ginger essential oil has the worst antibacterial effect.

4.2. MIC Determination of Six Essential Oils. As shown in Figure 2, cinnamon essential oil has the best bacteriostatic effect, followed by ginger essential oil and thyme essential oil. When the concentration of cinnamon essential oil was $0.006 \%$, there were colonies in the medium. However, when the concentration reached $0.06 \%$, cinnamon essential oil could completely inhibit the growth of bacteria in the culture dish. The MIC of cinnamon essential oil is $0.06 \%$. When the concentration of thymol essential oil is greater than $0.0012 \%$ and less than $0.065 \%$, there is bacterial growth in Petri dishes. When the concentration reaches $0.126 \%$, thyme essential oil will completely inhibit the growth of the flora. Therefore, the MIC value of cinnamon essential oil is $0.126 \%$. When the concentration of ginger essential oil is less than $0.026 \%$, bacteria grow in the culture dish. When the concentration is higher than $0.09 \%$, ginger essential oil will completely inhibit the growth of bacteria, so the MIC value of cinnamon essential oil is $0.09 \%$. The MIC value of Zanthoxylum bungeanum essential oil was $0.36 \%$. The MIC value of clove essential oil is $0.06 \%$.

4.3. Orthogonal Test Results. As shown in Table 2, the MIC values of six essential oils against a specific bacterium were taken as reference, and they were set to the highest concentration of each influencing element, and then orthogonal experiment was conducted. The factors affecting the bacteriostatic effect are cumin essential oil $>$ Zanthoxylum bungeanum Maxim >cinnamon essential oil > ginger essential oil $>$ thyme essential oil $>$ clove essential oil. According to the experimental results, the best compound essential oil concentration can be calculated as follows: cumin essential oil $0.82 \%$, Zanthoxylum $0.69 \%$, cinnamon essential oil $0.45 \%$, ginger essential oil $0.4 \%$, and thyme essential oil $0.35 \%$.

4.4. Effect of Compound Preservative Solution on $p H$ Value of Beef. As shown in Figure 3, the $\mathrm{pH}$ value of fresh meat ranges from 5.7 to 6.3 , the $\mathrm{pH}$ value of lower grade fresh meat is 6.3-6.5, and the $\mathrm{pH}$ value of processed meat is greater than 6.5. With the increase of storage time, the $\mathrm{pH}$ value of three groups of samples first shows a downward trend and then increases gradually. After anaerobic fermentation, the slaughtered fresh beef produces lactic acid 


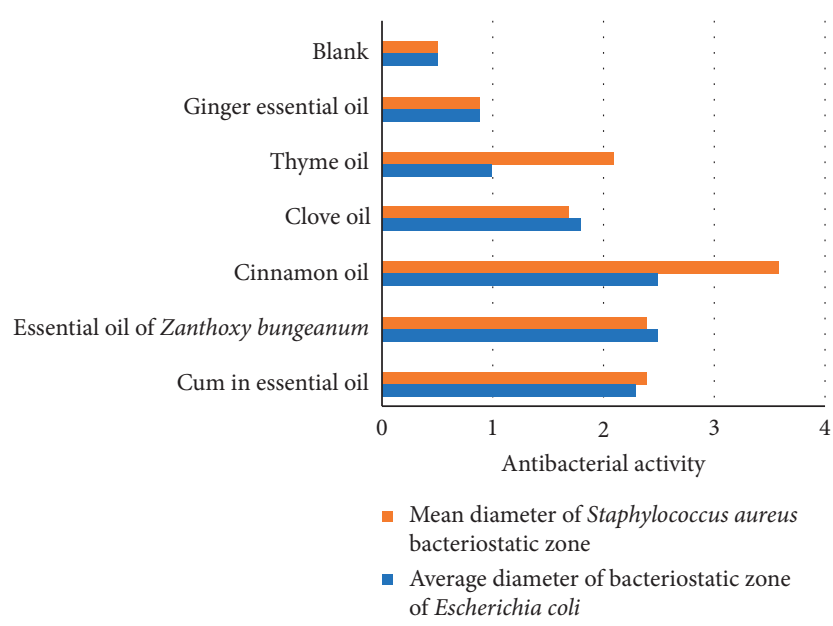

FIGURE 1: Determination of bacteriostatic zone of six essential oils against two kinds of bacteria.

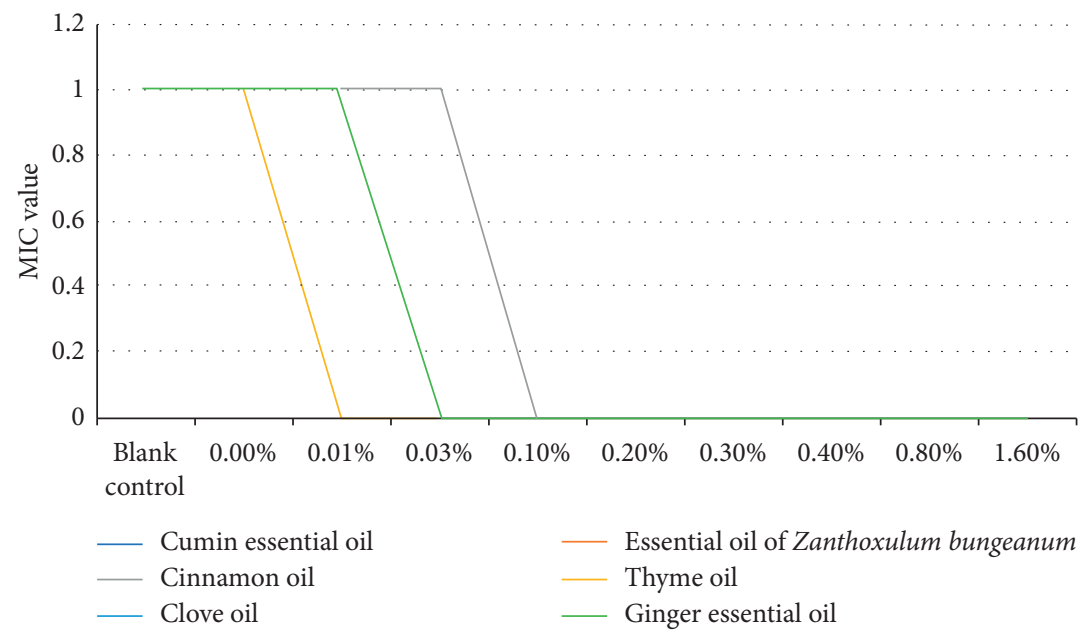

FIgURE 2: Minimum inhibitory concentration of six essential oils.

TABLE 2: Orthogonal experiment table.

\begin{tabular}{|c|c|c|c|c|c|c|c|c|c|c|}
\hline $\begin{array}{l}\text { Experiment } \\
\text { number }\end{array}$ & $\begin{array}{c}\text { Cumin } \\
\text { essential } \\
\text { oil } \\
\end{array}$ & $\begin{array}{c}\text { Essential oil of } \\
\text { Zanthoxylum } \\
\text { bungeanum }\end{array}$ & $\begin{array}{c}\text { Cinnamon } \\
\text { oil }\end{array}$ & $\begin{array}{c}\text { Clove } \\
\text { oil }\end{array}$ & $\begin{array}{c}\text { Thyme } \\
\text { oil }\end{array}$ & $\begin{array}{c}\text { Ginger } \\
\text { essential } \\
\text { oil }\end{array}$ & Blank & $\begin{array}{l}\text { Diameter of } \\
\text { bacteriostatic } \\
\text { zone } 1(\mathrm{~cm})\end{array}$ & $\begin{array}{c}\text { Diameter of } \\
\text { bacteriostatic } \\
\text { zone } 2(\mathrm{~cm})\end{array}$ & $\begin{array}{c}\text { Average } \\
\text { diameter } \\
(\mathrm{cm})\end{array}$ \\
\hline 1 & 1 & 1 & 1 & 1 & 1 & 1 & 1 & 1.2 & 1.4 & 1.3 \\
\hline 2 & 1 & 2 & 2 & 2 & 2 & 2 & 2 & 1.2 & 1.2 & 1.2 \\
\hline 3 & 1 & 3 & 3 & 3 & 3 & 3 & 3 & 1.5 & 1.55 & 1.53 \\
\hline 4 & 2 & 2 & 1 & 2 & 2 & 3 & 3 & 1.5 & 1.45 & 1.47 \\
\hline 5 & 2 & 2 & 2 & 3 & 3 & 3 & 1 & 1.8 & 1.5 & 1.65 \\
\hline 6 & 2 & 2 & 3 & 3 & 1 & 2 & 2 & 1.5 & 1.3 & 1.4 \\
\hline 7 & 3 & 3 & 3 & 1 & 3 & 3 & 2 & 1.8 & 1.9 & 1.85 \\
\hline 8 & 3 & 3 & 3 & 2 & 1 & 3 & 3 & 1.6 & 1.6 & 1.6 \\
\hline 9 & 3 & 3 & 3 & 3 & 2 & 2 & 1 & 1.8 & 1.6 & 1.7 \\
\hline$K 1$ & 4.30 & 4.70 & 4.30 & & & & & & & \\
\hline$K 2$ & 4.40 & 4.50 & 4.5 & & & & & & & \\
\hline K3 & 5.01 & 4.6 & 4.95 & & & & & & & \\
\hline$K 1$ & 1.45 & 1.55 & 1.45 & & & & & & & \\
\hline$K 2$ & 1.50 & 1.51 & 1.51 & & & & & & & \\
\hline K3 & 1.71 & 1.55 & 1.66 & & & & & & & \\
\hline$R$ & 0.29 & 0.07 & 0.25 & & & & & & & \\
\hline
\end{tabular}




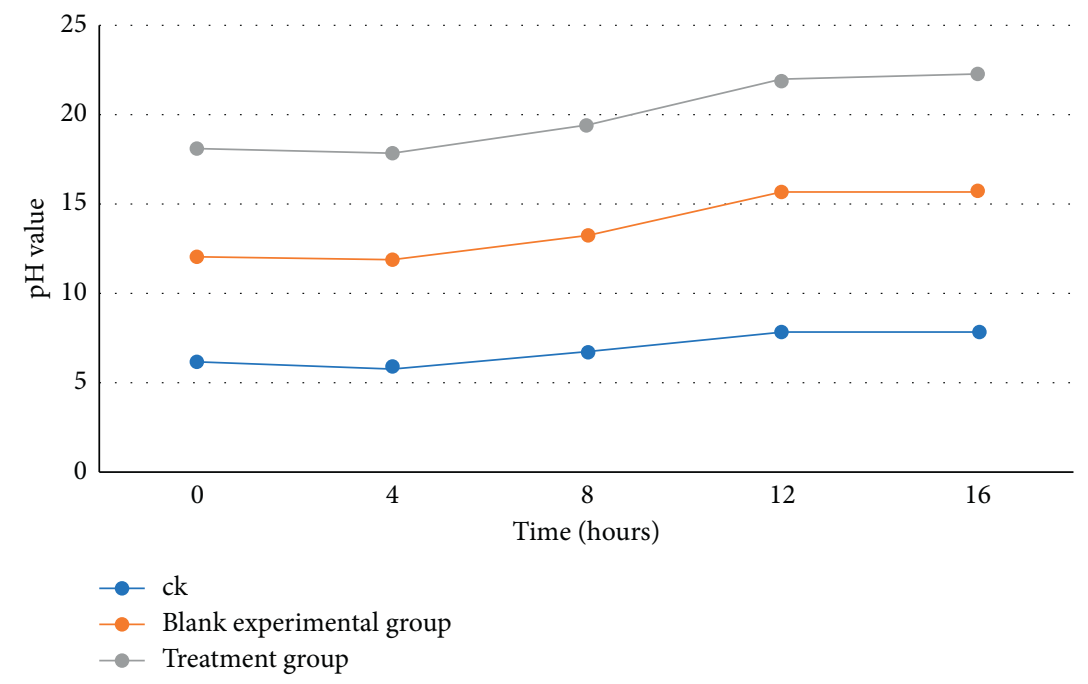

Figure 3: $\mathrm{pH}$ value of coated beef.

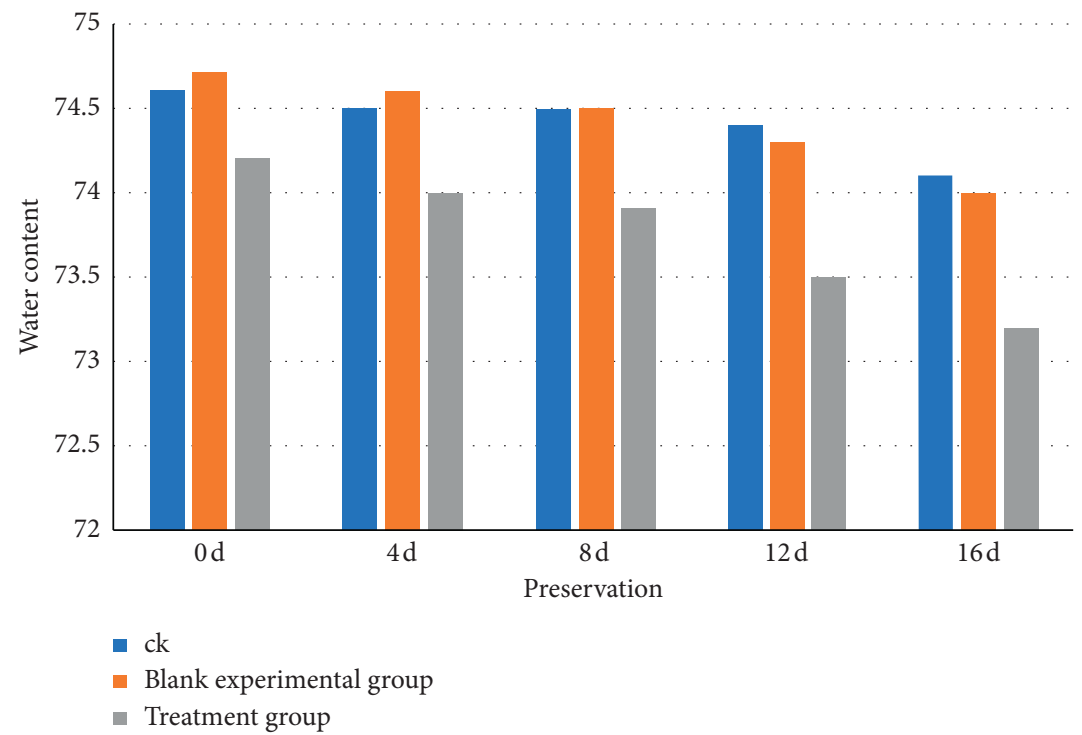

Figure 4: Changes of water content of beef after coating preservation treatment.

and phosphoric acid, which makes the $\mathrm{pH}$ value of meat decrease. In the process of meat ripening and storage, the endogenous proteases and microorganisms in meat can produce proteolytic enzymes, which can decompose muscle proteins into polypeptides and amino acids and generate basic groups. In this process, the $\mathrm{pH}$ value of meat increases. During storage, the $\mathrm{pH}$ values of blank group and control group were mostly the same, and the difference between them was not obvious. The $\mathrm{pH}$ value of blank group increased to 6.60 , which did not conform to the $\mathrm{pH}$ value of subfresh meat, and the meat sample of blank group became deteriorated meat. The $\mathrm{pH}$ value of the control group increased to $6.60 \%$, and the $\mathrm{pH}$ value of the treatment group became 5.89 , which was $10.67 \%$ and $11.21 \%$ lower than that of the blank group and the control group, respectively. The $\mathrm{pH}$ value of the two groups was still within the range of the $\mathrm{pH}$ value of fresh meat. At the 19th hour, the $\mathrm{pH}$ value of the treatment group changed to 6.21 , and the $\mathrm{pH}$ value of the control group and the blank group was 7.82 and 7.67, respectively. According to the above experimental results, it can be concluded that the application of plant essential oil to beef samples can adjust the $\mathrm{pH}$ value of beef and slow down the protein degradation of beef muscle.

4.5. Effect of Compound Preservative Solution on Water Content of Beef. As shown in Figure 4, with the increase of storage time, the water content of the three groups of experimental meat samples decreased, but the difference between the control group and the blank group was small. The difference between the treatment group and the control group and the blank group began to become obvious on the 16th day. In conclusion, the water content of the control group and the blank group did not change significantly. The 
water content of the blank group changed by $0.75 \%$ from the 0 th day to the 16 th day and decreased by $0.61 \%$ in the control group and $1.11 \%$ in the treatment group. Compared with the control group, the dosage of the control group decreased by $10.0 \%$. This may be due to the osmotic effect. After the essential oil was applied to the beef sample, the concentration outside the cell was higher, and the concentration inside the cell was lower, which resulted in the osmotic effect. The water molecule changed from the low concentration part to the high concentration part, and the water molecule transferred from the inside of the cell to the outside of the cell. From the overall situation, the water content of the treatment group decreased the most, but the water content of the three groups of experimental meat samples changed little during the experiment. It can be concluded that the operation of applying plant essential oil to beef has little effect on the moisture content of beef.

\section{Conclusion}

In this article, the application of natural essential oil nanocapsules in cold fresh beef insurance is studied. Through a comparative study of six essential oils of cumin, pepper, cinnamon, thyme, clove, and ginger, a more practical nanopreservation is developed. In this study, chitosan was used as the core material to prepare chitosan natural nanoessential oil. The nanoessential oil capsule was applied to the preservation of chilled beef. It was found that nanocapsule could slow down lipid oxidation in beef and effectively inhibit the growth of microorganisms in beef. By comparing the antibacterial activity of six essential oils, it was found that cinnamon essential oil had the strongest inhibitory effect on bacteria, while ginger essential oil had the worst antibacterial effect. When the MIC concentration of ginger essential oil is higher than $0.09 \%$, ginger essential oil can completely resist the growth of bacteria, so the MIC concentration of cinnamon oil should be set above $0.09 \%$. The best concentration of six essential oils was tested by bacteriostatic effect and other factors: cumin essential oil $0.82 \%$, Zanthoxylum content $0.69 \%$, cinnamon essential oil $0.45 \%$, ginger essential oil $0.4 \%$, and thyme essential oil $0.35 \%$. The $\mathrm{pH}$ value of fresh meat is $5.7-6.3$, and that of other fresh meat is 6.3-6.5. After the experimental treatment, the $\mathrm{pH}$ value of the prepared meat is greater than 6.5 , and the $\mathrm{pH}$ value of the three groups of samples shows a downward trend at first and then increases gradually. Proteases and microorganisms in cooked beef can produce proteolytic enzymes, and the storage time of degraded beef is very short, but plant essential oil can help reduce the degradation rate and prolong the storage time. Compared with the control group, the decrease of beef moisture in the treatment group was $10.51 \%$ more than that in the control group and $0.33 \%$ more than that in the blank group. Although the application of essential oil has little effect on inhibiting the water loss of beef, it still has a small effect. In this experiment, chitosan natural essential oil nanocapsules were prepared by nanoencapsulation of compound essential oil. This product was applied to the preservation of chilled beef, and the storage time was much better than before, which provided a theoretical reference for the research of new natural preservatives for chilled beef.

\section{Data Availability}

The data used in this article are available from the corresponding author upon request.

\section{Conflicts of Interest}

The authors declare that there are no conflicts of interest.

\section{Acknowledgments}

This work was supported by the Project of Agricultural Product Quality Safety Risk Assessment of China (No. GJFP202001503) and the Project of Special Funds for Basic Scientific Research Operating Expenses of Public Research Institutes at the Central Level (No. 1610322020019).

\section{References}

[1] M. Alagupalamuthirsolai, S. J. Ankegowda, M. Murugan, R. Sivaranjani, B. Rajkumar, and H. J. Akshitha, "Influence of light intensity on photosynthesis, capsule yield, essential oil and insect pest incidence of small cardamom (Elettaria cardamomum (L.) Maton)," Journal of Essential Oil Bearing Plants, vol. 22, no. 5, pp. 1172-1181, 2019.

[2] N. Wang, X. T. Wang, Z. D. Wang, and W. Ding, "Effect of electron beam irradiation dose on the quality of vacuumpackaged chilled fresh beef," Modern Food Ence and Technology, vol. 31, no. 7, pp. 241-247, 2015.

[3] E. Oberhofnerová, M. Pánek, and M. Bhm, "Effect of surface pretreatment with natural essential oils on the weathering performance of spruce wood," Bioresources, vol. 13, no. 3, pp. 7053-7070, 2018.

[4] H. Gong, Z. Yang, M. Liu et al., "Time-dependent categorization of volatile aroma compound formation in stewed Chinese spicy beef using electron nose profile coupled with thermal desorption GC-MS detection," Food Science and Human Wellness, vol. 6, no. 3, pp. 137-146, 2017.

[5] J. Mehrdad, G. Ahmad, A. K. Omid, and A. Shima, "Improving postharvest vase-life and quality of cut gerbera flowers using natural and chemical preservatives," Journal of Central European Agriculture, vol. 16, no. 2, pp. 199-211, 2015.

[6] S. S. García, E. C. Hellen, A. Manuel, M. Gracia, and I. Silvia, "Evaluation of the antimicrobial activity and cytotoxicity of different components of natural origin present in essential oils," Molecules, vol. 23, no. 6, p. 1399, 2018.

[7] M. Dmitruk, A. Sulborska, B. Żuraw, E. Stawiarz, and E. Weryszko-Chmielewska, "Sites of secretion of bioactive compounds in leaves of Dracocephalum moldavica L.: anatomical, histochemical, and essential oil study," Brazilian Journal of Botany, vol. 42, no. 4, pp. 701-715, 2019.

[8] A. Bezysov, H. Dubova, and N. Rogova, "New methods of plant selection for food aroma recovery aided by oxidation processes," Acta Universitatis Cibiniensis. Series E: Food Technology, vol. 19, no. 2, pp. 15-26, 2015.

[9] L. M. Xia, L. L. Cui, Y. L. Jiang et al., "Meta-analysis of clinical efficacy of traditional Chinese medicine in the treatment of aplastic anemia," World Journal of Traditional Chinese Medicine, vol. 3, no. 4, pp. 457-467, 2017. 
[10] Y. Yuan, M. F. Li, W. S. Chen et al., "Microencapsulation of shiitake (Lentinula edodes) essential oil by complex coacervation: formation, rheological property, oxidative stability and odour attenuation effect," International Journal of Food Science \& Technology, vol. 53, no. 7, pp. 1681-1688, 2018.

[11] H. Rezaeinia, B. Ghorani, B. Emadzadeh, and N. Tucker, "Electrohydrodynamic atomization of balangu (Lallemantia royleana) seed gum for the fast-release of Mentha longifolia L. essential oil: characterization of nano-capsules and modeling the kinetics of release," Food Hydrocolloids, vol. 93, pp. 374-385, 2019.

[12] B. Grzesiak, B. Kołodziej, G. Anna, and H. Krukowski, "The effect of some natural essential oils against bovine mastitis caused by Prototheca zopfii isolates in vitro," Mycopathologia, vol. 183, no. 4, pp. 1-10, 2018.

[13] M. Mahboubi, "Management of acute cough by Zataria multiflora boiss as an alternative treatment," Journal of Integrative Medicine, vol. 16, no. 1, pp. 20-25, 2018.

[14] M. M. Elghandour, M. Z. Salem, R. Greiner, and A. Z. Salem, "Effects of natural blends of garlic and eucalypt essential oils on biogas production of four fibrous feeds at short-term of incubation in the ruminal anaerobic biosystem," Journal of the Science of Food and Agriculture, vol. 99, no. 2, pp. 967-968, 2019. 